\title{
Differences in cardiovascular responses to supine exercise and to standing after exercise in two clinical subgroups of Shy-Drager syndrome (multiple system atrophy)
}

\author{
G D P Smith, C J Mathias
}

\begin{abstract}
Background-In chronic autonomic failure of varying aetiologies, there are differences in the cardiovascular responses to supine leg exercise and to standing after exercise. Whether this occurs between the different subgroups with Shy-Drager syndrome (SDS) is unknown. Methods-Fourteen patients with the cerebellar form (SDS-C) and 11 patients with parkinsonian features (SDS-P) were studied.

Results-Both groups had a similar degree of autonomic failure and postural hypotension. Their responses were compared with nine patients with idiopathic Parkinson's disease (IPD) and 15 normal subjects (controls), all with normal autonomic function.
\end{abstract}

With supine exercise, blood pressure and heart rate rose similarly in controls and patients with IPD and there was no fall in blood pressure on standing after exercise. In both SDS groups there were abnormal responses to exercise: blood pressure fell in SDS-C, but did not fall or rise in SDS-P. Heart rate increased similarly in both SDS groups, calculated systemic vascular resistance fell similarly, but cardiac index rose more in SDS-P than SDS-C. Resting plasma noradrenaline concentrations were subnormal in both forms of SDS, and did not increase with exercise. Postural hypotension was enhanced after exercise to the same extent in SDS-C and SDS-P.

Conclusions-The greater cardiovascular abnormalities in response to exercise in SDS-C suggests that cerebellar or brain stem autonomic pathways are impaired to a greater extent in SDS-C than in SDS-P. Pooling SDS subgroups, therefore, may obscure pathophysiological differences to certain stimuli. Clinically when postural hypotension is being assessed, separation of the subgroups may not be essential, as they responded similarly.

(F Neurol Neurosurg Psychiatry 1996;61:297-303)

Keywords: Shy-Drager syndrome; idiopathic Parkinson's disease; cardiovascular responses; exercise

Supine exercise in central autonomic failure due to Shy-Drager syndrome (SDS) and peripheral autonomic failure due to pure autonomic failure (PAF) cause a pronounced fall in blood pressure ${ }^{1-3}$ and an increase in postural hypotension after exercise. ${ }^{4}$ In these studies the patients with SDS (defined as primary autonomic failure with additional neurological features of unknown aetiology, and similar to multiple system atrophy with autonomic failure) were pooled and the different clinical subgroups were not assessed separately. Clinically these consist of the cerebellar form with or without pyramidal features (SDS-C), a parkinsonian form (SDS-P), and a mixed form with a combination of these features (SDS-M). ${ }^{5}$ Studies in other disorders with autonomic failure (familial amyloidosis, dopamine $\beta$-hydroxylase deficiency, and diabetes mellitus) ${ }^{46}$ indicate differences in responses to exercise. As exercise may unmask differences within the subgroups which are of pathophysiological relevance we studied the blood pressure responses to supine exercise in two distinct clinical subgroups, one with cerebellar manifestations (SDS-C) and the other with parkinsonian features (SDS-P). Haemodynamic and plasma catecholamine measurements were made to determine the mechanisms for possible differences, if present. The blood pressure response to standing before and after exercise was also measured, as this is of importance in the clinical setting in diagnosis, evaluation of progression, and the response to treatment. Comparisons were made with patients with idiopathic Parkinson's disease (IPD) having a similar degree of motor disability and with normal subjects (controls) having normal autonomic function.

\section{Patients and methods}

PATIENTS

Twenty five patients with Shy-Drager syndrome were studied. All patients with SDS had clinically significant autonomic involvement, including sympathetic vasoconstrictor failure with a systolic blood pressure fall of more than $20 \mathrm{~mm} \mathrm{Hg}$ and cardiac parasympathetic impairment on physiological testing (table)..$^{7}$ They were divided into two clinical subgroups on the basis of their additional neurological features; those with cerebellar features were grouped as SDS-C (14 patients, nine men, mean age 59, range 41 to 74 years) and those with parkinsonian features were classified as SDS-P (11 patients, 11 men, mean age 62 , range 44 to 76 years). Patients with mixed neurological features (SDS-M) were excluded from this study. The disease was of similar duration in the two groups (mean 3.9 (range 1-10) years in SDS-C and 
Summary of physiological testing in normal subjects (controls), patients with idiopathic Parkinson's disease (IPD) and patients with Shy-Drager syndrome with cerebellar (SDSC) or parkinsonian ( $S D S-P)$ forms

\begin{tabular}{lllll}
\hline & $\begin{array}{l}\text { Controls } \\
(n=15)\end{array}$ & $\begin{array}{l}I P D \\
(n=8)\end{array}$ & $\begin{array}{l}S D S-C \\
(n=14)\end{array}$ & $\begin{array}{l}S D S-P \\
(n=11)\end{array}$ \\
\hline $\begin{array}{l}\text { Postural hypotension }(>20 \mathrm{~mm} \mathrm{Hg} \text { systolic) } \\
\text { Valsalva's manoeuvre }\end{array}$ & - & - & + & + \\
$\begin{array}{l}\text { Pressor tests: } \\
\quad \text { Mental arithmetic }\end{array}$ & $\mathrm{N}$ & $\mathrm{N}$ & $\mathrm{A}$ & $\mathrm{A}$ \\
$\quad \begin{array}{l}\text { Cutaneous cold } \\
\quad \text { Isometric exercise }\end{array}$ & $\mathrm{N}$ & $\mathrm{N}$ & $\mathrm{A}$ & $\mathrm{A}$ \\
Sinus arrhythmia to deep breathing & $\mathrm{N}$ & $\mathrm{N}$ & $\mathrm{A}$ & $\mathrm{A}$ \\
Heart rate response to hyperventilation & $\mathrm{N}$ & $\mathrm{N}$ & $\mathrm{A}$ & $\mathrm{A}$ \\
& $\mathrm{N}$ & $\mathrm{A}$ & $\mathrm{A}$ \\
\hline
\end{tabular}

+ = Present; - = absent; $\mathrm{N}=$ normal; $\mathrm{A}=$ abnormal.

mean $3 \cdot 7$ (range 2-10) years in SDS-P). In none of the patients with SDS was there an aetiological factor to account for either the autonomic failure or neurological deficits; they all had the clinical features consistent with a diagnosis of multiple system atrophy (MSA) along with definite autonomic failure. The two distinct clinical forms of MSA have been previously described along with the mixed form. ${ }^{58}$ In the cerebellar form the clinical features consisted of lower limb or truncal ataxia, usually with progressive involvement of the upper limbs, causing an intention tremor; many of the patients had scanning dysarthria and nystagmus. In the parkinsonian form there was often bilateral involvement, with akinesia and rigidity and usually minimal or no tremor; all had a suboptimal or an absent response to levodopa. In neither group was there a downgaze palsy, absent tendon reflexes, or dementia. Both groups had features of urinary dysfunction with urgency, frequency, and incontinence, along with impotence in the men.

The responses of patients with SDS were compared with eight patients with untreated idiopathic Parkinson's disease (IPD; seven men, mean age 56, range 37 to 67 years) and 15 normal control subjects (eight men, mean age 60 , range 48 to 73 years). Patients with IPD who had not been on previous antiparkinsonian treatment were chosen as this might have interfered with the haemodynamic responses. They had early Parkinson's disease, with a typical onset of unilateral rigidity, hypokinesia, and tremor and without any additional neurological features of other parkinsonian syndromes. They had a Hoehn and Yahr staging of 1 or $2^{9}$ and thus had a similar motor disability to the SDS-P group. None, however, had abnormal autonomic function or a fall in blood pressure on standing or head up tilt. It is unlikely that they had an early form of SDS or MSA as all had normal autonomic function, a unilateral onset of parkinsonian features, and a subsequent favourable response to levodopa, all of which were consistent with classic IPD. The control subjects, like the patients with IPD, had normal autonomic tests without postural hypotension (table). The study was performed with the understanding and consent of each subject and was approved by the ethics committee of The National Hospital for Neurology and Neurosurgery.
METHODS

All studies were performed at 0900 hours in a temperature controlled clinical laboratory (average temperature $24 \pm 2^{\circ} \mathrm{C}$ ) after an overnight fast. All medication was stopped at least 72 hours before the study, except for low dose fludrocortisone in the patients with SDS, with the last dose taken the previous night. None of the patients were on antiparkinsonian medication. The patients with IPD had never had levodopa. The patients with SDS-P had not had levodopa within the previous two months. A cannula (venflon) was inserted into a vein in the antecubital fossa for blood sampling. Blood pressure and heart rate were recorded, with the arm held stationary at the side of the body, using an automated sphygmomanometer (Dinamap), which was calibrated against a mercury sphygmomanometer. Blood pressure readings with this machine have been validated against intra-arterial recordings. ${ }^{10}$ After 30 minutes of supine rest, the degree of postural hypotension was measured after two and five minutes of standing. After a further 30 minutes of rest, the subjects exercised in the supine position by pedalling a cycle ergometer at workloads of 25, 50, and 75 W, each for three minutes. The workload was strictly adhered to, to ensure a comparable degree of exercise between the different groups. Measurements were made at the end of each stage of exercise and continued for a further 10 minutes after exercise while supine. The degree of postural hypotension was then reassessed after exercise.

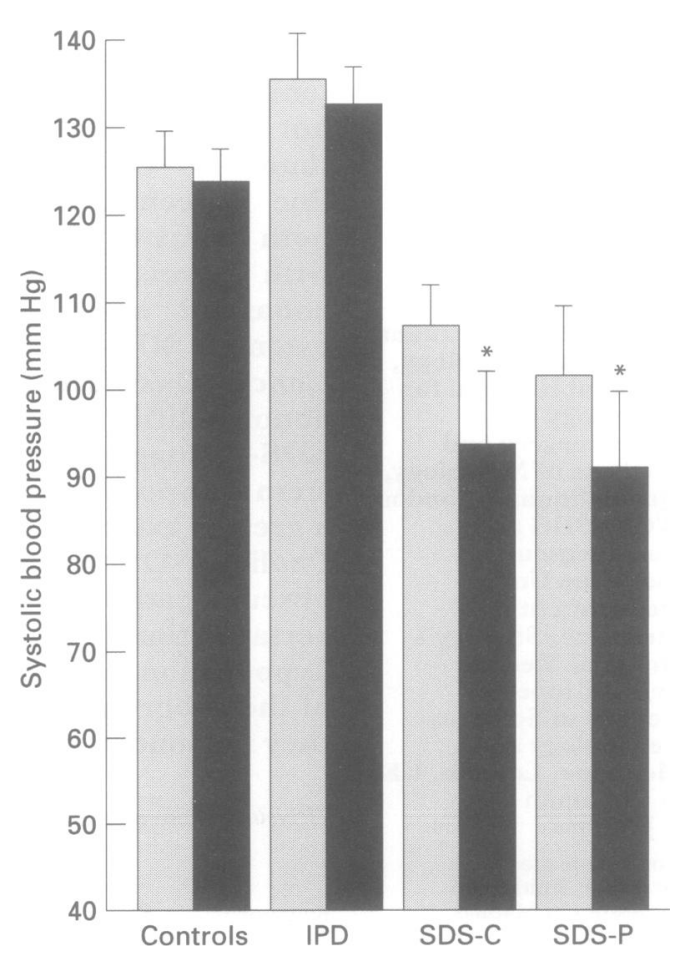

Figure 1 Systolic blood pressure on standing before (grey bar) and after (black bar) exercise in controls, patients with idiopathic Parkinson's disease (IPD), and patients with Shy-Drager syndrome with the cerebellar (SDS-C) and parkinsonian $(S D S-P)$ forms. ${ }^{\star} P<0.05$, before $v$ after exercise. 
Figure 2 Changes in systolic and diastolic blood pressure (SBP and DBP) and heart rate, during and after supine exercise in normal controls, patients with idiopathic Parkinson's disease (IPD), and patients with Shy-Drager syndrome with the cerebellar (SDS-

C) and parkinsonian

( $S D S-P$ ) form.

${ }^{\star} P<0.05 ; * * P<0.001$ $\star * * P<0.0001$, changes from baseline.
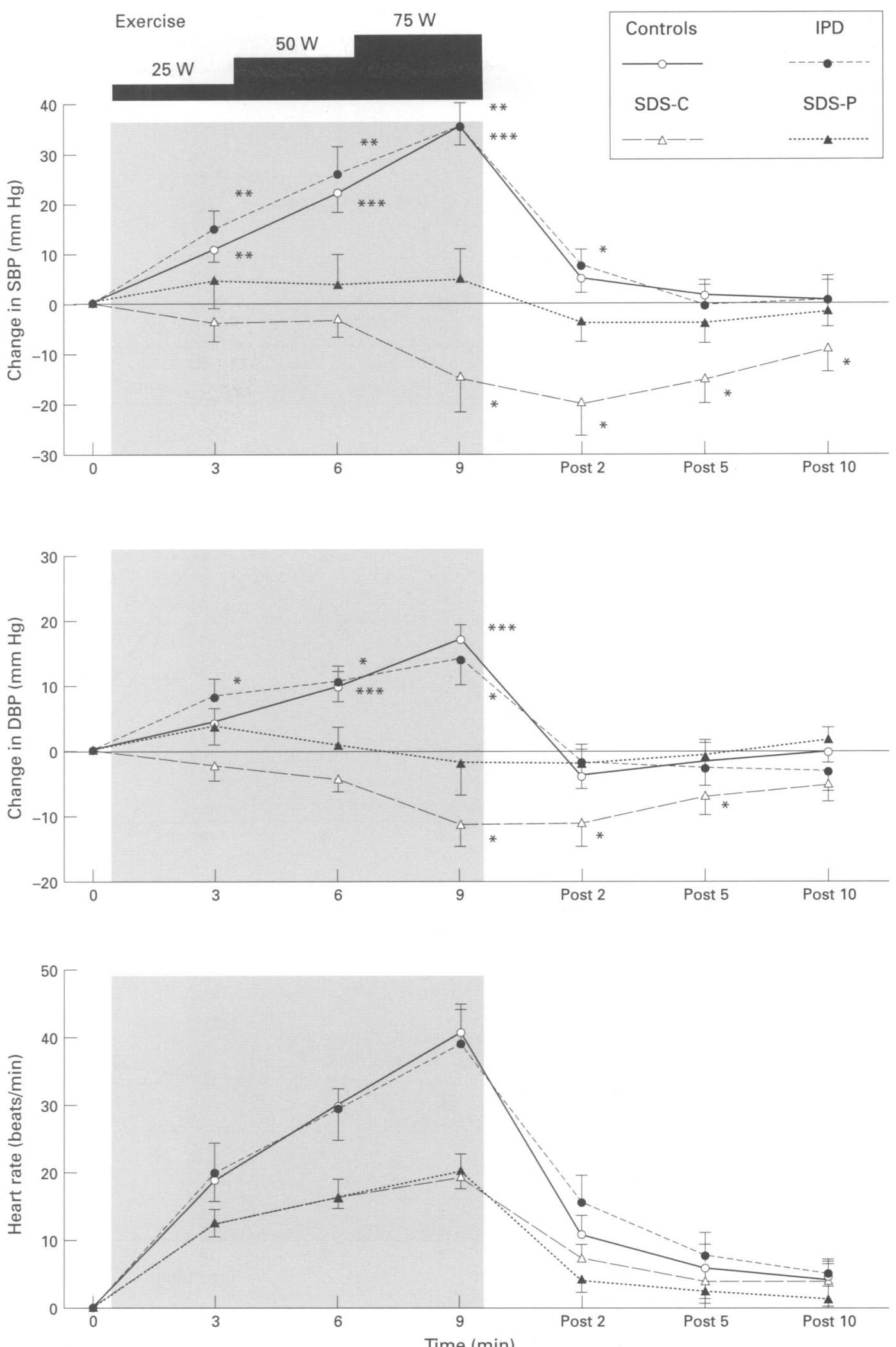

The following additional measurements were made in the supine position at rest, at the end of each stage of exercise, and after exercise for 10 minutes: cardiac index (CI), as a measure of cardiac output, was calculated by multiplying stroke distance (SD) by heart rate; SD was derived from the integral of peak velocity profile of ascending aortic blood flow, measured by a continuous wave Doppler ultrasound technique (Exerdop; Quinton Instrument $\mathrm{Co}$ ). A mean velocity of 20 consecutive cardiac cycles were taken for each observation. This technique has been validated as a measure of cardiac output at rest ${ }^{11}$ and with exercise ${ }^{12}$ and has been used previously with supine exercise..$^{1314}$ Mean arterial blood pressure (MAP) was calculated from the diastolic blood pressure (DBP) $+1 / 3$ of the pulse pressure, and index of systemic vascular resistance (SVR) was calculated from MAP/CI. At three, six, and nine minutes of exercise and 10 minutes after exercise, venous blood was collected into heparinised tubes with added 1,2-di-(2-aminoethoxy)-ethane- 
Figure 3 Changes in stroke distance, cardiac index, and systemic

vascular resistance (SVR) during and after supine exercise in normal controls, patients with idiopathic Parkinson's disease (IPD), and patients with Shy-

Drager syndrome with the cerebellar (SDS-C) and parkinsonian (SDS-P)

form. ${ }^{\star} P<0.05$ ${ }_{\star \star *} P<0.001$ $\star \star \star P<0.0001$, changes from baseline.
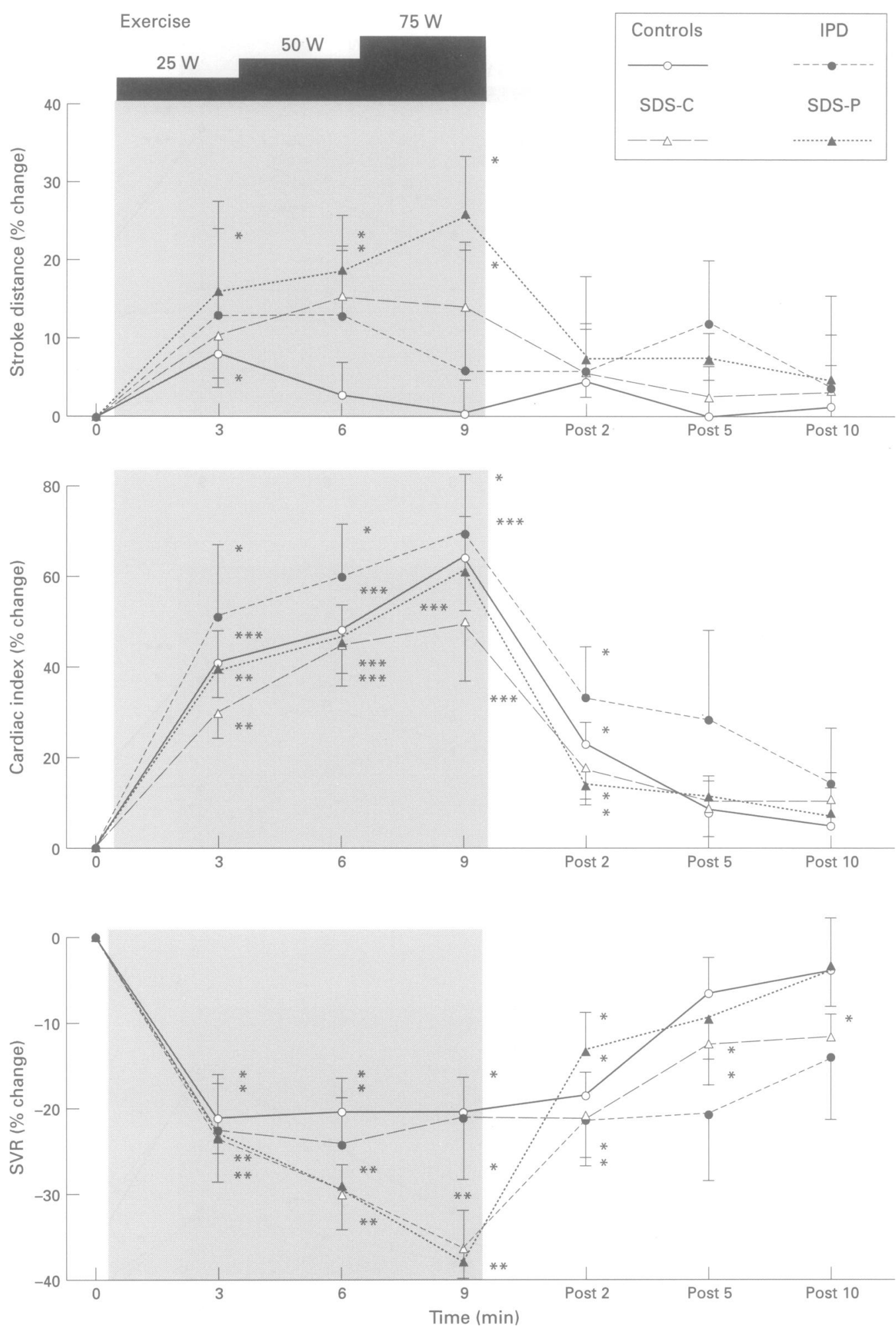

NNN'n'-tetra-acetic acid (EGTA) and glutathione to prevent oxidation. Samples were kept on ice until centrifuged and the plasma then kept at $-20^{\circ} \mathrm{C}$ until assayed. Plasma noradrenaline, adrenaline, and dopamine were measured by high performance liquid chromatography with an electrochemical detector. ${ }^{15}$

Results are expressed as means (SEM). Statistical analyses were performed using paired $t$ tests for comparing changes within subject groups and analyses of variance (ANOVA) and independent $t$ tests for com- paring between subject groups. A $\mathbf{P}$ value $<0.05$ was considered significant. Non-significant changes are expressed as NS.

\section{Results}

BLOOD PRESSURE

Resting supine blood pressure in controls was (122(4)/75(3) $\mathrm{mm} \mathrm{Hg}$ and was higher in IPD (138(5)/85(3) $\mathrm{mm} \mathrm{Hg}$, each $\mathrm{P}<0.05)$, SDSC $(149(6) / 90(3) \mathrm{mm} \mathrm{Hg}, \quad P<0.0005$ and $\mathrm{P}<0.005)$ and SDS-P $(144(5) / 90(4) \mathrm{mm} \mathrm{Hg}$, each $P<0.05$; fig 1$)$. Some patients with SDS 
were unable to remain standing for five minutes, especially after exercise, and, therefore, only data after two minutes of standing are provided. On standing before exercise, blood pressure did not fall in controls or patients with IPD. In patients with SDS-C there was a postural blood pressure fall of $41(7) / 21(5) \mathrm{mm}$ $\mathrm{Hg}$ and in SDS-P of 45(8)/20(5) $\mathrm{mm} \mathrm{Hg}$.

With exercise, there was a similar increase in blood pressure in controls (by 35(4)/17(3) $\mathrm{mm} \mathrm{Hg}$ at the end of nine minutes of exercise, each $P<0.0001$ ), and IPD (by 35(6)/14(4) $\mathrm{mm} \mathrm{Hg}, \mathrm{P}<0.001$ and $\mathrm{P}<0.01)$; blood pressure fell in SDS-C (by 15(6)/11(3) $\mathrm{mm} \mathrm{Hg}$, $P<0.05$ and $P<0.01$ ), with no change in SDS-P (5(6)/ 2(5) mm Hg, NS; fig 2). In the controls and patients with IPD, supine blood pressure had returned to resting values by five minutes after exercise. In patients with SDSC, supine blood pressure was still lower 10 minutes after exercise $(139(5) / 84(4) \mathrm{mm} \mathrm{Hg})$ than at rest $(148(5) / 89$ (3) $\mathrm{mm} \mathrm{Hg}, \mathrm{P}<0.05$ and NS). In patients with SDS-P, supine blood pressure remained unchanged after exercise.

On standing, there was no fall in postural blood pressure in controls and patients with IPD either before or after exercise. In SDS, blood pressure fell to a lower value on standing after exercise than before exercise both in SDS-C (108(4)/68(4) $\mathrm{mm} \mathrm{Hg}$ before and $94(6) / 61(5) \mathrm{mm} \mathrm{Hg}$ after, each $\mathrm{P}<0.01$ ) and SDS-P (102(9)/68(5) $\mathrm{mm} \mathrm{Hg}$ before and 92(9)/60(5) $\mathrm{mm} \mathrm{Hg}$ after, each $\mathrm{P}<0.05$; fig 1).

\section{HEART RATE}

Resting heart rate was similar between controls (69(2)) and IPD (73(6)), SDS-C $(68(3))$, and SDS-P groups (71(3)). With exercise, there was a similar rise in heart rate in controls (41(3)) and IPD (40(5)), with a smaller rise in SDS-C $(20(2))$ and SDS-P (21(2), ANOVA P < 0.001; fig 2). After exercise, heart rate rapidly decreased, but was still above resting values 10 minutes after exercise in all groups. On standing, heart rate increased in all groups, and the increase was marginally higher on standing after than before exercise in all groups.

STROKE DISTANCE, CARDIAC INDEX, AND INDEX OF SYSTEMIC VASCULAR RESISTANCE Assessment of stroke volume and cardiac output depend on aortic diameter, which was not measured; basal SD and CI values, therefore, have not been compared between the two groups. The percentage change in SD and CI are independent of aortic diameter and therefore, have been compared during and after exercise (fig 3). With exercise, SD did not change in controls $(0(5) \%, N S)$ or IPD $(6(16) \%$, NS), but increased in SDS-C $(14(7) \%, P<0.05)$ and SDS-P $(26(8) \%$, $P<0.01)$; the increase in SDS-C and SDS-P was greater than in controls and was higher in SDS-P than in SDS-C (each $P<0.05$ ). With exercise, $\mathrm{CI}$ increased to the same degree in controls $(64(10) \%)$, IPD $(70(23) \%)$, SDS-C $(50(120 \%)$, and SDS-P (61(11)\%); in SDS-C the mean level was lower than SDS-P but this difference was not significant. After exercise, CI rapidly returned towards baseline in controls, SDS-C, and SDS-P, but both SD and $\mathrm{CI}$ remained raised for longer after exercise in IPD.

With exercise, calculated SVR fell to the same degree in controls (by 22(4)\%) and IPD (by $21(13) \%$ ), but was greater in SDS-C (by $36(5) \%, P<0.05)$ and SDS-P (by $37(3) \%$, $\mathbf{P}<0.01)$.

\section{PLASMA CATECHOLAMINES}

Resting venous plasma noradrenaline concentration was similar in controls $(313(43) \mathrm{pg} / \mathrm{ml}$ ) and IPD (301(86) pg/ml), but lower in SDS-C (207(38) $\mathrm{pg} / \mathrm{ml}, \quad \mathrm{P}<0.05)$ and SDS-P (201(39) $\mathrm{pg} / \mathrm{ml}, \mathrm{P}<0.05)$. With exercise, plasma noradrenaline concentration increased in controls (to 502(65) $\mathrm{pg} / \mathrm{ml}, \mathrm{p}<0.001$ ), with a similar increase in IPD (to 526(226) $\mathrm{pg} / \mathrm{ml}, \mathrm{P}<0.05)$. There was a smaller increase in SDS-C (to $252(35) \mathrm{pg} / \mathrm{ml}, \mathrm{P}<0.005$ ) and SDS-P (to 231(59) pg/ml, $\mathrm{P}<0.005$ ). Resting venous plasma adrenaline concentrations were not significantly different between controls (30(6) $\mathrm{pg} / \mathrm{ml}), \mathrm{IPD}(48(10) \mathrm{pg} / \mathrm{ml})$ and SDS-P $(20(5) \mathrm{pg} / \mathrm{ml})$, with unrecordable concentrations in all but two of the patients with SDS$\mathrm{C}$; there was no significant change with exercise in any group.

Venous plasma dopamine was below detectable concentrations $(<20 \mathrm{pg} / \mathrm{ml})$ before and at the end of exercise in most controls and patients with IPD, SDS-C, or SDS-P.

\section{Discussion}

In a previous study in primary autonomic failure there were small differences in the haemodynamic responses to supine exercise in patients with SDS and patients with pure autonomic failure, ${ }^{3}$ and both had a larger fall in blood pressure on standing after exercise. ${ }^{4}$ It was initially assumed that the cardiovascular responses to exercise and to standing after exercise were similar in autonomic failure of different aetiologies, but this was not the experience in further studies. In autonomic failure due to familial amyloid polyneuropathy and in selective sympathetic failure due to dopamine $\beta$-hydroxylase deficiency, blood pressure remained unchanged with exercise. Unlike normal subjects it did not rise, but neither did it fall as in patients with PAF or SDS; however, in both there was an increase in postural hypotension on standing after exercise. ${ }^{4} 6$ The responses in diabetic autonomic neuropathy varied further, with neither supine hypotension nor an enhancement of postural hypotension after exercise (unpublished data). Various explanations have been suggested to account for the different cardiovascular responses in autonomic failure of varying aetiologies, ranging from the site of the lesion and degree of autonomic impairment to direct involvement of target organs. An important factor is likely to be the site of the autonomic lesion and the ability to recruit compensatory mechanisms. ${ }^{3}$ Many patients with SDS, especially in the 
early stages, have neurological signs consistent with a lesion affecting either the cerebellar or striatonigral pathways. In a previous series from this unit, at diagnosis $20 \%$ had the cerebellar, 30\% had the parkinsonian, and the rest had the mixed form, with a combination of these neurological features. ${ }^{5}$ The patients with SDS-C, who are likely to have the histological features of olivopontocerebellar atrophy, are more likely to have a greater degree of cardiovascular dysfunction, because these regions are closely concerned with cardiovascular autonomic control. We studied two clear clinical subgroups of SDS to detect differences unmasked by exercise and subsequent postural change. We recognise that SDS is a progressive disorder, that there may be subclinical central involvement of other systems even in the distinct SDS-P or SDS-C forms, and that in due course many patients develop a combination of neurological features. In a recent postmortem study in multiple system atrophy (many patients of whom had autonomic failure and thus were similar to the patients we describe with SDS), histological evidence of cerebellar pathology was found even in those with only parkinsonian features. ${ }^{8}$ This also may have occurred in our patients with SDS$P$, although it was likely that they had less advanced disease than those reported postmortem.

We studied patients with IPD without autonomic failure as a further "control" group, as they had similar motor deficits to patients with SDS-P. The haemodynamic responses to exercise and standing after exercise in patients with IPD were similar to those in normal subjects. Autonomic failure, however, may complicate IPD, and these results may not be applicable to IPD in general as in the later stages, especially with the added affect of antiparkinsonian drugs, the responses to exercise may be affected.

In SDS-C, supine exercise resulted in a fall in both systolic and diastolic blood pressure, with a slow recovery to baseline after exercise. By contrast, in patients with SDS-P there was no change in blood pressure either during or after exercise. The lack of fall in blood pressure with exercise in SDS-P warrants explanation. Both patients with SDS-C and those with SDS-P had a similar degree of autonomic failure as based on the degree of postural hypotension and on routine autonomic testing. The patients with SDS-P had bradykinesia, but the degree of exercise was closely supervised to ensure equivalent workloads and excluded less physical exertion. The heart rate response was identical in the two groups, but there was a larger increase in stroke volume in patients with SDS-P. In patients with SDS-C, the fall in blood pressure was similar to the response found in patients with $\mathrm{PAF}^{3}$ in whom the blood pressure fall is probably caused by vasodilatation in exercising skeletal muscle, without adequate compensatory vasoconstriction in other vascular regions. It was unlikely that in patients with SDS-P there was a greater activation of compensatory vasoconstrictor pathways, as there was a similar fall in systemic vascular resistance and a similar rise in concentration of noradrenaline as in patients with SDS-C. In patients with SDS-P, however, the greater increase in stroke volume which resulted in levels of cardiac output similar to controls, may have buffered and prevented the fall in blood pressure. Speculation on the reasons for the differences include the site of the lesion, which is more rostral in SDS-P and may have spared the central pathways involved in this response. In SDS-C, the differences may have been magnified because of disruption of cerebellar centres involved in cardiovascular control. Animal studies implicate the uvula of the posterior cerebellar vermis in the autonomic control of cardiovascular activity $^{16}$ and studies in cats suggest that cerebellar activity augments sympathetic output and inhibits parasympathetic output. ${ }^{17}$ Also, brainstem structures are more likely to have been affected in SDS-C. Brainstem regions such as the rostroventrolateral medulla, and the nucleus tractus solitari, among others, are known to be involved closely in cardiovascular control. ${ }^{18} 19$

Although there were clear differences in the supine blood pressure responses to exercise, the postural blood pressure response to standing after exercise was enhanced similarly in SDS-C and SDS-P. Peripheral vasoconstriction, which is largely dependent on the sympathetic outflow, is probably of greater importance than cardiac changes in responding to gravitational change. As vascular resistance was similarly affected with exercise in SDS-C and SDS-P, this may account for why blood pressure fell to the same extent with standing after exercise in both groups.

In conclusion, this study indicates that varying stimuli, in this case exercise and head up postural change, result in different responses in two subgroups (SDS-C and SDS-P) of the same disorder, despite their having a similar degree of postural hypotension. This is likely to be explained by differences in the site of the lesion. Definition of the neurological features in addition to the autonomic deficits, and separation of the clinical subgroups, is likely to be important when determining cardiovascular autonomic responses to certain physiological stimuli. Of clinical relevance, however, was the postural fall in blood pressure after exercise, which was enhanced to a similar degree in both groups, despite the different supine blood pressure response. Thus in the clinical context this separation may not be essential, especially if directed mainly towards the evaluation of postural hypotension.

We thank the Brain Research Trust and the Wellcome Trust for their support.

1 Marshall RJ, Schirger A, Shepherd JT. Blood pressure during supine exercise in idiopathic orthostatic hypotension. Circulation 1961;24:76-81.

2 Bevegård $\mathrm{S}$, Jonsson $\mathrm{B}$, Karlof $\mathrm{I}$. Circulatory response to recumbent exercise and head-up tilting in patients with disturbed sympathetic cardiovascular control (postural hypotension). Acta Medica Scandinavia 1962;172: 623-36.

3 Smith GDP, Watson LP, Pavitt DV, Mathias CJ. Abnormal cardiovascular and catecholamine responses to supine exercise in human subjects with sympathetic dysfunction. $\mathcal{F}$ Physiol (Lond) 1995;484:255-65.

4 Smith GDP, Mathias CJ. Postural hypotension enhanced 
by exercise-observations in three groups with chronic by exercise observations in three groups

5 Bannister R, Mathias CJ, Polinsky RJ. Autonomic failure: a comparison between UK and US experience. In: comparison between UKnister R, Mathias CJ, eds. A textbook of clinical disorders Bannister R, Mathias CJ, eds. A textbook of clinical disorders
of the autonomic nervous system. 2nd ed. Oxford: Oxford of the autonomic nervous system.

6 Smith GDP, Mathias CJ. Abnormal blood pressure response to exercise in familial amyloid polyneuropathy type 1, with autonomic impairment; comparison with pure autonomic failure [abstract]. $\mathcal{f}$ Neurol 1994;241 (suppl 1):534.

7 Mathias CJ, Bannister R. Investigation of autonomic disorders. In: Bannister R, Mathias CJ, eds. Autonomic failure. $A$ textbook of clinical disorders of the autonomic nervous system, 3rd ed. Oxford: Oxford University Press, 1992: tem, 3 rd

8 Wenning GK, Ben-Shlomo Y, Magalhaes M, Daniel SE, Quinn NP. Clinicopatholical study of 35 cases of multiQuinn NP. Clinicopatholical study of 35 cases of multi-
ple system atrophy. $₹$ Neurol Neurosurg Psychiatry 1995; ple system

9 Hoehn MM, Yahr MD. Parkinsonism: onset, progression and mortality. Neurology 1967;17:427-42.

10 Nystrom E, Reid KH, Bennet R, Couture L, Edmonds HL. A comparison of two automated indirect arterial blood pressure meters: with recordings from a radial arterial catheter in anesthetized surgical patients. Anesthesiology 1985;62:526-30.

11 Huntsman LL, Stewart DK, Barnes SR, Franklin SB, Colocousis JS, Hessel EA. Noninvasive Doppler determination of cardiac output in man. Circulation 1983;67:
593-602.

12 Mehta N, Iyawe VI, Cummin ARC, Bayley S, Saunders KB, Bennet ED. Validation of a Doppler technique for $\mathrm{KB}$, Bennet ED. Validation of a Doppler technique for beat to beat measu.

13 Loeppky JA, Greene ER, Hoekenga DE, Caprihan A, Left UC. Beat-by-beat stroke volume assessment by pulsed Doppler in upright and supine exercise. $\mathcal{F} A p p l$ Physiol 1981;50:1173-82.

14 Eriksen M, Waaler BA, Walloe L, Wesche J. Dynamics and dimensions of cardiac output changes in humans at the onset and at the end of moderate rhythmic exercise. $\mathcal{F}$ Physiol (Lond) 1990;426:423-37.

15 May C, Ham IW, Heslop K, Stone FA, Mathias CJ. Intravenous morphine causes hypotension, hypoglyIntravenous morphine causes hypotension, hypoglyconscious rat. Clin Sci 1988;75:71-7.

16 Paton JFR, Spyer KM. Cerebellar cortical regulation of circulation. NIPH Ann 1992;7:124-9.

17 Chen CH, Williams JL, Lutherer LO. Cerebellar lesions alter autonomic responses to transient isovolaemic alter autonomic responses to transient isovolaemic 263-72.

18 Brown GL, Guyenet PG. Electrophysiological study of cardiovascular neurones in the rostral ventrolateral medulla in rats. Circ Res 1985;56:359-69.

19 Spyer KM. Central nervous control of the cardiovascular ststem. In: Bannister R, Mathias CJ, eds. Autonomic failure. A textbook of clinical disorders of the autonomic nervous system. 3rd ed. Oxford University Press, Oxford 1992: $54-77$.

\section{NEUROLOGICAL STAMP}

\section{David Livingstone (1813-73)}

Livingstone graduated in medicine at the Faculty of Physicians and Surgeons in Glasgow in 1840. He had offered his services in 1838 to the London Missionary Society. His ambition had been to go to China, but as Britain was at war with China (the opium war) that was impossible and he was sent to Africa. He travelled over a third of the continent and as a result of his explorations the map changed profoundly. He gave an accurate description of African sleeping sickness and its transmission by the tsetse fly. The trypanosome, which enters the central nervous system, often after many years, had yet to be discovered.

From 1866 he was lost to the world for five years while he wandered over vast tracks of Africa making valuable observations but losing his health and strength. As a missionary he was a great pioneer opening up the whole of Central Africa to the influences of Christianity and his observations and reports after encountering the famous Arab slave dealer Tippoo Tib were important in the abolition of the slave trade.

With his disappearance he was believed dead, and the New York Herald sent HM Stanley to search for him. When he finally located him in Ujiuji, Stanley uttered the famous remark, "Dr Livingstone, I presume". Stanley

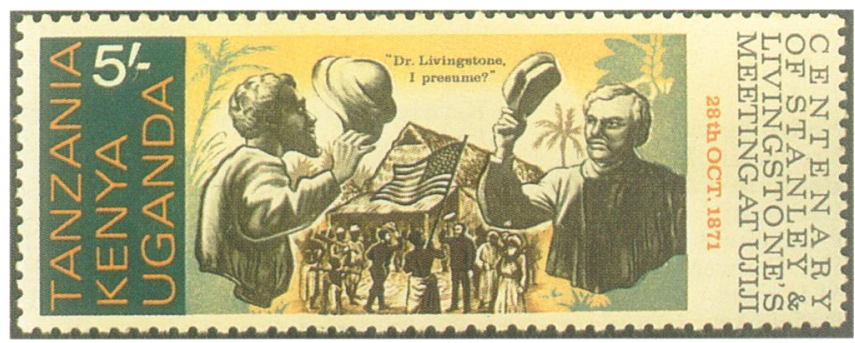

gave Livingstone, who was sick, desperately needed food and medicine but could not persuade him to leave Africa with him. Livingstone died in Africa two years later, in 1873. He is buried in Westminster Abbey. Before his burial his body was examined at the headquarters of the Royal Geographical Society so that a positive identification could be made. After 11 months his features were unrecognisable, but a lump in the left humerus where it had been shattered by a lion nearly thirty years earlier allowed identification. Livingstone has been honoured a number of times on stamps as an explorer. The stamp issued by Kenya, Uganda, and Tanganyika in 1971 (Stanley Gibbons 63, Scott 237) illustrates the meeting between Livingstone and Stanley. 